\title{
A novel sustainable decision making model for municipal solid waste management
}

\author{
Ming-Lung Hung, Hwong-wen Ma *, Wan-Fa Yang \\ Graduate Institute of Environmental Engineering, National Taiwan University, 71 Chou-Shan Road, Taipei 106, Taiwan, ROC
}

Accepted 4 January 2006

Available online 10 March 2006

\begin{abstract}
This paper reviews several models developed to support decision making in municipal solid waste management (MSWM). The concepts underlying sustainable MSWM models can be divided into two categories: one incorporates social factors into decision making methods, and the other includes public participation in the decision-making process. The public is only apprised or takes part in discussion, and has little effect on decision making in most research efforts. Few studies have considered public participation in the decisionmaking process, and the methods have sought to strike a compromise between concerned criteria, not between stakeholders. However, the source of the conflict arises from the stakeholders' complex web of value. Such conflict affects the feasibility of implementing any decision. The purpose of this study is to develop a sustainable decision making model for MSWM to overcome these shortcomings. The proposed model combines multicriteria decision making (MCDM) and a consensus analysis model (CAM). The CAM is built up to aid in decision-making when MCDM methods are utilized and, subsequently, a novel sustainable decision making model for MSWM is developed. The main feature of CAM is the assessment of the degree of consensus between stakeholders for particular alternatives. A case study for food waste management in Taiwan is presented to demonstrate the practicality of this model.
\end{abstract}

(c) 2006 Elsevier Ltd. All rights reserved.

\section{Introduction}

Several models have been developed in recent decades to support decision making in municipal solid waste management (MSWM). In the 1970s, the goals of the MSWM model were simple and narrow, such as optimizing waste collection routes for vehicles (Truitt et al., 1969) or locating appropriate transfer stations (Esmaili, 1972; Helms and Clark, 1974). In the 1980s, the focus was extended to encompass MSWM on a system level, minimizing MSWM cost (Hasit and Warner, 1981; Jenkins, 1982; Perlack and Willis, 1985). In the 1990s, the factors considered in MSWM models were principally economic (e.g., system cost and system benefit), environmental (air emission, water pollution) and technological (the maturity of technology). Two decision-making models, multiobjective pro-

\footnotetext{
* Corresponding author. Tel.: +88622363 0406; fax: +886223928830.

E-mail addresses: d89541004@ntu.edu.tw (M.-L. Hung), hwma@ ntu.edu.tw (H.-w. Ma), wfyang@ntu.edu.tw (W.-F. Yang).
}

gramming (MOP) and multicriteria decision making (MCDM), as well as an environmental impact assessment model, the life cycle assessment (LCA), were often used to aid the decision-making in MSWM. Numerous studies applied LCA to evaluate the environmental impact of MSWM alternatives. (Barton et al., 1996; Powell et al., 1996; Finnveden, 1999; Powell, 2000). Some of these methods were further developed for simulation modeling, such as ORWARE (Dalemo et al., 1997; Sonesson et al., 1997; Eriksson et al., 2002) and EUGENE (Berger et al., 1999). Multiobjective programming is a popular method utilized to solve MSWM problems, such as locating sites, and choosing alternatives or strategies (Alidi, 1996; Chang and Hwang, 1996; Chang and Wang, 1996; Chang and Wei, 1999). MCDM is also a commonly used method to resolve MSWM problems. The characteristic of MCDM is that it facilitates choosing the best alternative among several alternatives by assessing numerous criteria. Many approaches are available for solving environmental problem with multiple criteria, including the AHP method 
(Haastrup et al., 1998; Chiou and Tzeng, 2002; Tran et al., 2002), outranking methods (Brans and Vincke, 1985; Roy, 1991; Geldermann et al., 2000), and the TOPSIS method (Hwang and Yoon, 1981).

In recent years, MSWM models have stressed "sustainability," and can be divided into two categories. One model category addresses social factors in the decision making methods (Beccali et al., 1998; Vaillancourt and Waaub, 2002; Klang et al., 2003), whereas the other model incorporates public participation into the decision making process (Bellehumeur et al., 1997; Vasseur et al., 1997; Ananda and Herath, 2003). Morrissey and Browne (2004) proposed that a sustainable MSWM model should be environmentally effective, economically affordable and socially acceptable. Wilson et al. (2001), who interviewed 11 different leadingedge European municipal solid waste programs in nine countries, proposed that "including different public groups in the process from the very beginning can help avoid the high levels of controversy and public opposition that have surrounded many MSW projects".

Public participation in a decision-making process can occur at one of three stages: scoping stage, a decision-making stage, and a policy active stage. Most research efforts have incorporated public participation into the scoping and policy active stages by utilizing policy education and public meetings. In these models, the public is only apprised or takes part in the discussion, and has little effect on decision-making outcomes. Few studies integrate public participation into the decision-making process; in these studies, MCDM methods are typically applied. In previous MCDM methods, two processes must be completed before obtaining a final solution (Bryson, 1996): the consensus process and the selection process. The consensus process addresses how to obtain maximum consensus or agreement among experts or stakeholders for a set of alternatives; whereas the selection process determines how to acquire a solution set of alternatives from expert opinions regarding alternatives. The public's involvement in the consensus processes is typically in weight setting. All methods seek a compromise solution among criteria, not between stakeholders. However, the source of conflict arises from the complex web of values held by stakeholders. Such conflict impacts the feasibility of implementing a decision. Although some studies have discussed the concept of consensus in relation to MCDM methods (Bryson, 1996; Tavana et al., 1996; Bordogna et al., 1997; Herrera et al., 2003; Chiclana et al., 2004), their focus has been on how to gain consensus, performance or decision.

This study presents a sustainable decision making-model that integrates the MCDM and consensus analysis model (CAM) for MSWM. The CAM is built up to aid decision making in traditional MCDM methods and to assess the degree of consensus between stakeholders for specific alternatives. The novel sustainable decision making model presented in this study has the following goals: (1) assist policy-makers when considering social aspects; (2) understand the degree of consensus among stakeholders regard- ing particular alternatives; and (3) help decision makers resolve potential conflicts during the decision-making stage.

The rest of this paper is structured as follows. Section 2 describes CAM, Section 3 then presents a sustainable decision-making model for waste management, and Section 4 discusses the food waste management system in Taipei City in Taiwan. Conclusions are drawn in Section 5 , and several advantages of the proposed model are pointed out.

\section{Consensus analysis model (CAM)}

This study proposes a novel approach for quantifying the degree of consensus and consensus results for stakeholders in an attempt to find a compromise solution between the stakeholders. The "degree of consensus" denotes the degree of similarity of preference between stakeholders and the "consensus results" signifies the average preference of all stakeholders. Fuzzy set theory is introduced to deal with linguistic variables in the CAM. The opinions of each stakeholder are investigated using a questionnaire, and stakeholder degree of consensus is then quantified for all alternatives. The CAM analyzes consensus among stakeholders and possible coalition formation based on proposed options. "Linguistic variables" are employed to identify stakeholder attitudes via a questionnaire and to establish a subjective decision matrix. Finally, stakeholder degree of consensus and consensus results are generated. The CAM has three principal objectives: first, to aid the decision-making methods; second, to determine the degree of consensus among stakeholders regarding specific alternatives; and third, to allow decision makers to resolve the conflicts among stakeholders during the decision-making stage. This method is comprised of two parts: if all the stakeholders have the same choice, then degree of consensus equals 1 and a large distance between stakeholder choices is positively correlated with possibility of conflict arising. The CAM procedures are as follows:

\subsection{Determining linguistic variables for alternative preferences}

Five levels (very good, good, moderate, bad, and very bad) of linguistic variables (Zimmermann, 1987) are used to integrate stakeholder preferences (Fig. 1).

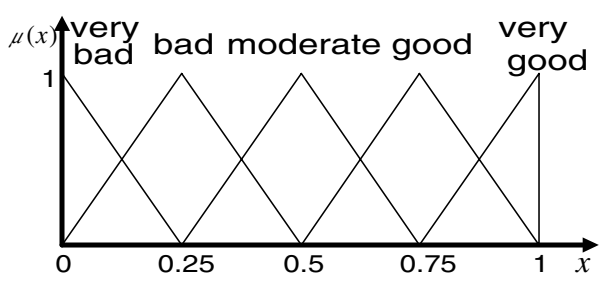

Fig. 1. Membership of five level linguistic variables. 
2.2. Building the fuzzy subjective decision matrix for each stakeholder

Since each stakeholder may comprise several members, and to respond to real situations, the model developed in this investigation first expresses stakeholder opinion regarding particular alternatives using a mathematical formula. Assume that $m$ stakeholders consider $n$ alternatives. The fuzzy subjective decision matrix for each stakeholder can be established as follows: fuzzy subjective decision matrix for each stakeholder $\tilde{x}_{i k}=\left[x_{i k}^{1}, x_{i k}^{\mathrm{m}}, x_{i k}^{\mathrm{r}}\right]$ :

$x_{i k}^{1}=\min \left\{x_{i j k}^{1}\right\} \quad \forall j, k$

$x_{i k}^{m}=\operatorname{geomean}\left\{x_{i j k}^{m}\right\} \quad \forall j, k$

$x_{i k}^{r}=\max \left\{x_{i j k}^{r}\right\} \quad \forall j, k$

where $x_{i k}^{1}$ denotes the left value (the minimum value in this study) of the fuzzy number of preference for alternative $k$ judged by stakeholder $i, x_{i k}^{\mathrm{m}}$ represents the medium value (the geometric average value in this study) of the fuzzy number of preference for alternative $k$ judged by stakeholder $i, x_{i k}^{\mathrm{r}}$ is the right value (the maximum value in this study) of the fuzzy number of preference for the alternative $k$ judged by the stakeholder $i, x_{i j k}^{1}$ denotes the left value of the fuzzy number of preference for alternative $k$ judged by member $j$ in stakeholder $i, x_{i j k}^{\mathrm{m}}$ represents the medium value of the fuzzy number of preference for alternative $k$ judged by member $j$ in stakeholder $i$, and $x_{i j k}^{\mathrm{r}}$ denotes the right value of the fuzzy number of preference for alternative $k$ judged by member $j$ in stakeholder $i$.

\subsection{Determining stakeholder preferences regarding alternatives}

The fuzzy subjective decision matrix can be established by defuzzifying the data using the centroid method (Solvmosi and Dombi, 1986):

fuzzy subjective decision matrix $F$

$$
=\left(\begin{array}{ccccc}
f_{11} & \cdots & \cdots & \cdots & f_{1 n} \\
\vdots & \ddots & & & \vdots \\
\vdots & & f_{i k} & & \vdots \\
\vdots & & & \ddots & \vdots \\
f_{m 1} & \cdots & \cdots & \cdots & f_{m n}
\end{array}\right)
$$

where $f_{i k}$ is the defuzzified value of stakeholders $i$ for alternative $k$.

\subsection{Calculating the consensus results for the alternatives (CR)}

The consensus results for each alternative can be expressed as the mean defuzzified value of the triangle fuzzy numbers for stakeholders as follows:
$\mathrm{CR}=\left[\bar{f}_{1}, \bar{f}_{2}, \ldots \bar{f}_{k}, \ldots, \bar{f}_{n}\right]$

where $\bar{f}_{k}$ is the average of the defuzzified value of all stakeholders for alternative $k$.

\subsection{Obtaining consensus degree for alternatives}

After the consensus results for the alternatives are determined, the consensus degree for these alternatives can also be defined. Degree of consensus is determined based on the concept of semantic distance. If stakeholder consensus results for particular alternatives are similar, opinions are compromised. The calculation of degree of consensus comprises three steps:

First, calculate a semantic standard deviation distance for each alternative $\left(\mathrm{sd}_{k}\right)$. The semantic standard deviation distance $\operatorname{sd}_{k}$ can be determined as the standard deviation of defuzzification of the linguistic variables for all the stakeholders for each alternative, and can be expressed as follows:

$\operatorname{sd}_{k}=\sqrt{\frac{\sum_{i=1}^{m}\left(f_{i k}-\bar{f}_{k}\right)^{2}}{m-1}}$

Second, the semantic distance is normalized $\left(d_{k}^{\text {norm }}\right)$. The normal semantic distance is normalized by the following equation:

$d_{k}^{\text {norm }}=\frac{\mathrm{sd}_{k}}{\mathrm{sd}^{*}}$

where $\mathrm{sd}^{*}$ is the maximum of all possible $\mathrm{sd}_{i}$.

When considering $m$ kinds of stakeholders, the number of possible $\operatorname{sd}_{i}$ is $H_{m}^{5}=C_{m}^{(5+m)-1}$. Meanwhile, Table 1 lists the results of $m=3-7$.

Third, degree of consensus is obtained for each alternative $\left(\mathrm{CD}_{k}\right)$. The consensus degree for each alternative is calculated using the following equation:

$\mathrm{CD}_{k}=1-d_{k}^{\text {norm }}$

\subsection{Plotting the consensus diagram and interpretation}

A consensus diagram is then plotted based on degree of consensus, as illustrated in the example provided in the example section.

The question then arises: What does "degree of consensus" actually mean, and what degree of agreement is required before consensus is achieved in regard to a particular decision? Of course, this question may be answered after this proposed model has been applied to numerous

Table 1

Number of the possible $\mathrm{sd}_{i}$ when different numbers of stakeholders are considered

\begin{tabular}{llllll}
\hline Number of stakeholders & 3 & 4 & 5 & 6 & 7 \\
\hline${\text { Possible } \mathrm{sd}_{i}}^{*}$ & 35 & 70 & 126 & 210 & 330 \\
sd $_{i}^{*}$ & 0.393 & 0.417 & 0.409 & 0.417 & 0.413 \\
\hline
\end{tabular}


case studies. However, this investigation proposes another route to answering this question. As the number of possible situations is known, if the degree of consensus exceeds a certain probability, then it can be said that a compromise (or acceptable level) has been reached, and the median is not a bad choice. Table 2 lists the degree of compromise

Table 2

Degree of compromise for consensus when different numbers of stakeholders are considered

\begin{tabular}{llllll}
\hline Number of stakeholders & 3 & 4 & 5 & 6 & 7 \\
\hline $\begin{array}{l}\text { Degree of compromise } \\
\text { for consensus }\end{array}$ & 0.500 & 0.426 & 0.385 & 0.396 & 0.377 \\
\hline
\end{tabular}

for consensus when different numbers of the stakeholders are considered. The degree of compromise for consensus decreases with larger numbers of the stakeholders, which is a rational relationship common in real world situations. Fig. 2 shows those stakeholder opinions in real situations for which the consensus degree is greater than or equal to the compromise degree of consensus under the situation of 3-7 stakeholders, respectively. For example, when there are three stakeholders, and one stakeholder chooses "very bad" and two stakeholders choose "moderate", then the degree of consensus is 0.500 , which is equal to the compromise degree of consensus, and hence a compromise could be deemed reached.

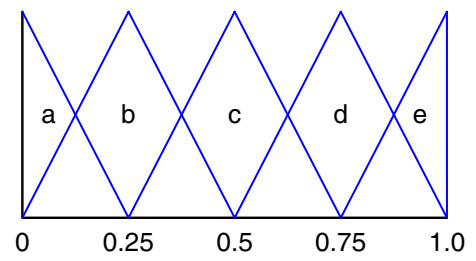

(1) $a=1, c=2, b=d=e=0$

(2) $a=2, c=1, b=d=e=0$

(3) $c=1, e=2, a=b=d=0$

(4) $c=2, e=1, a=b=d=0$

$C D=0.500$ (when the number of stakeholders is equal to three)

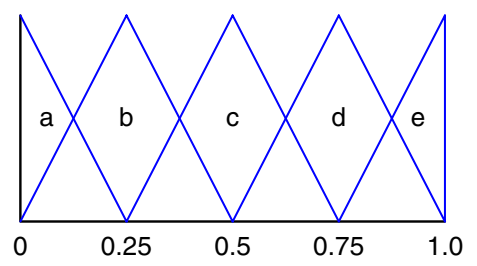

(1) $a=d=1, c=2, b=e=0$

(2) $b=e=2, c=2, a=d=0$

$C D=0.426$ (when the number of stakeholders is equal to four)

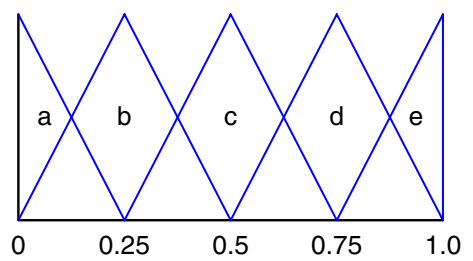

(1) $a=b=2, d=1, c=e=0$

(2) $d=e=2, b=1, a=c=0$

(3) $b=3, d=2, a=c=e=0$

(4) $b=2, d=3, a=c=e=0$

$C D=0.401$ (when the number of stakeholders is equal to five)

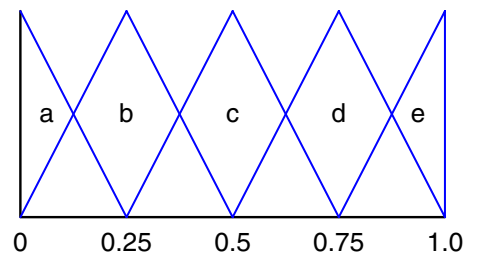

(1) $b=d=3, a=c=e=0$

$C D=0.400$ (when the number of stakeholders is equal to six)

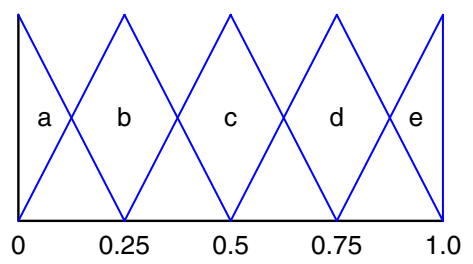

(1) $a=d=2, c=3, b=e=0$

(2) $b=e=2, c=3, a=d=0$

$C D=0.381$ (when the number of stakeholders is equal to seven) where

$a$ is the number of the stakeholder whose opinion is "very bad"

$b$ is the number of the stakeholder whose opinion is "bad"

$\mathrm{c}$ is the number of the stakeholder whose opinion is "moderate"

$d$ is the number of the stakeholder whose opinion is "good"

$e$ is the number of the stakeholder whose opinion is "very good"

Fig. 2. Stakeholder opinions in real situations for which the consensus degree is greater than or equal to the compromise degree of consensus under the situation of 3-7 stakeholders. 


\section{A novel sustainable decision making model for waste management}

This study presents a novel sustainable decision making model for MSWM. Fig. 3 displays the outline of the algorithm, and the main steps are as follows.

\subsection{Formulate the model for waste management problems}

Real world waste management problems require the consideration of numerous factors - environmental, economic, social, etc. Multiple stakeholders criteria can be for- mulated. Stakeholders in waste problems can generally be divided into the government sector, experts, non-governmental organizations and business. Each stakeholder category also normally contains several members. For example, a non-governmental organization may be a coalition of several environmental protection groups, related associations, etc.

\subsection{Prioritize the alternatives}

Many MCDM methods, such as ELECTRE (Roy, 1991), PROMETHEE (Brans and Vincke, 1985), TOPSIS

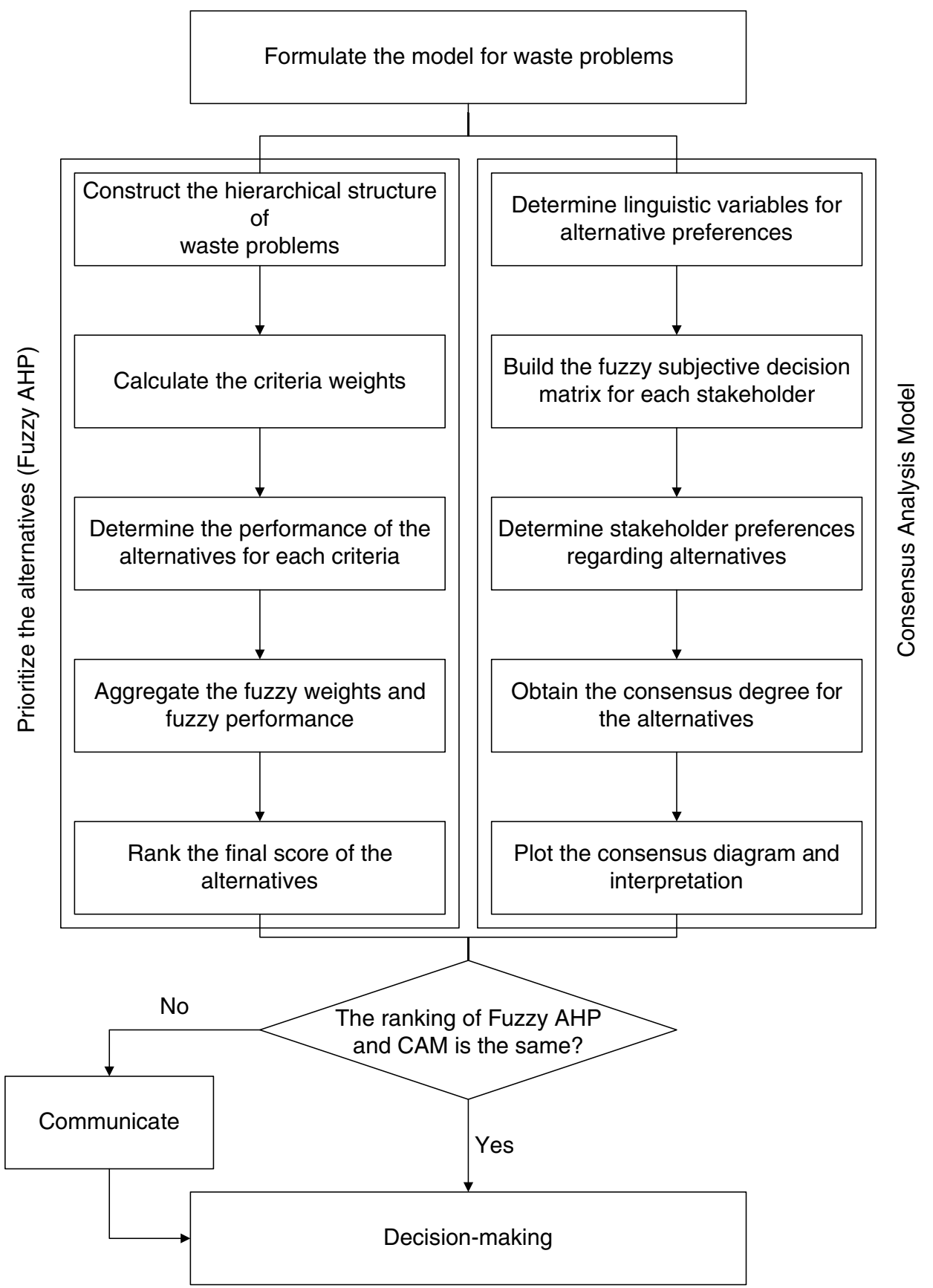

Fig. 3. Steps of a sustainable decision making model for waste management. 
(Hwang and Yoon, 1981), and AHP (Saaty, 1980) can be used to prioritize alternatives. The AHP method is the most popular of these approaches. However, real world waste management decision-making involves numerous stakeholders with different viewpoints, meaning that the conventional AHP method is insufficient. Buckley (1985) applies the fuzzy theory to the AHP method to avoid neglecting extreme values. Application of the fuzzy AHP method requires the following five steps.

\subsubsection{Construct the hierarchical structure of waste problems}

For MCDM problems, the evaluation process must be divided into distinct stages. First, an overall objective is set based on a general problem statement. Second, based on stakeholders' perspectives, problems are classified into distinct aspects. Third, by defining alternatives/strategies and criteria, a discrete MCDM problem comprising of a finite set of alternatives/strategies can be assessed in terms of multiple criteria.

\subsubsection{Calculate the criteria weights}

Criteria weights can be determined by stakeholders. To comprise all stakeholders options, this study used the fuzzy weighting method.

\subsubsection{Determine the fuzzy performance of the alternatives for each criterion}

Criteria can usually be divided into two categories: quantitative and qualitative. Performance of the alternative criteria can be calculated as follows.

Quantitative criteria. This investigation utilized the triangular fuzzy number to express the performance of quantitative criteria. First, the original value of the quantitative criteria is normalized and expressed as follows:

$x_{i j}^{\mathrm{norm}}=\frac{x_{j}^{\max }-x_{i j}^{0}}{x_{j}^{\max }-x_{j}^{\min }}, \quad i=1 \sim n$ (positive criteria)

$x_{i j}^{\mathrm{norm}}=\frac{x_{i j}^{0}-x_{j}^{\min }}{x_{j}^{\max }-x_{j}^{\min }}, \quad i=1 \sim n$ (negative criteria)

where $n$ denotes the number of alternatives, $x_{i j}^{\text {norm }}$ represents the normalized value of criteria $j$ for alternative $i, x_{i j}$ is the value of criteria $j$ for alternative $i, x_{j}^{\max }$ denotes the maximum value of criteria $j$ for all alternatives, and $x_{j}^{\min }$ represents the minimum value of criteria $j$ for all alternatives.

Second, the normalization value is fuzzified using the following equation:

fuzzy performance of quantitative criteria $\widetilde{x_{i j}}$

$$
=\left(0.9 \cdot x_{i j}^{\mathrm{norm}}, x_{i j}^{\mathrm{norm}}, \min \left(1.1 \cdot x_{i j}^{\mathrm{norm}}, 1\right)\right)
$$

Qualitative criteria. Linguistic variables are designed to express the words or sentences in a natural or artificial language (Zimmermann, 1987). Five levels are used to integrate preferences of field experts. The fuzzy performance of qualitative criteria is then determined using a fuzzy triangular number.
3.2.4. Aggregate the fuzzy weights and fuzzy performance

A simple additive method is utilized to aggregate the fuzzy weights and fuzzy performance, i.e.:

$$
\begin{aligned}
\widetilde{R} & =\widetilde{X} \otimes \widetilde{W}^{T}=\tilde{x}_{i j} \otimes \widetilde{W}^{T}=\left(\begin{array}{ccc}
\tilde{x}_{11} & \cdots & \tilde{x}_{1 m} \\
\vdots & \ddots & \vdots \\
\tilde{x}_{n 1} & \cdots & \tilde{x}_{n m}
\end{array}\right) \otimes\left[\begin{array}{c}
\widetilde{w}_{1} \\
\vdots \\
\widetilde{w}_{m}
\end{array}\right] \\
& =\left(\begin{array}{c}
\tilde{x}_{11} \otimes \tilde{w}_{1} \oplus \tilde{x}_{12} \otimes \tilde{w}_{2} \oplus \cdots \oplus \tilde{x}_{1 m} \otimes \tilde{w}_{m} \\
\vdots \\
\widetilde{x}_{n 1} \otimes \widetilde{w}_{1} \oplus \widetilde{x}_{n 2} \otimes \widetilde{w}_{2} \oplus \cdots \oplus \widetilde{x}_{n m} \otimes \widetilde{w}_{m}
\end{array}\right)
\end{aligned}
$$

where $\widetilde{R}$ denotes fuzzy evaluation matrix, $\widetilde{X}$ presents fuzzy performance matrix, and $\widetilde{W}$ is fuzzy weighting matrix.

\subsubsection{Rank final scores of alternatives}

The centroid weights method (Solvmosi and Dombi, 1986 ) is used to defuzzify the fuzzy numbers and prioritize alternatives.

\subsection{Consensus analysis model}

In addition to prioritizing alternatives, measuring the degree of consensus among stakeholders regarding alternatives is needed. The CAM was described in detail in Section 2.

\subsection{Communicate and decision-making}

A decision maker can make a decision by considering both MCDM and CAM, not only to seek a compromise solution between criteria, but also to pay attention to the degree of consensus for all alternatives. This method can assist decision makers in resolving possible conflicts during the decision-making stage.

\section{Illustrative example}

The novel sustainable decision-making model of waste management is applied to evaluate a food waste management problem in Taipei City, Taiwan. Taipei City's population density is the highest in Taiwan. Food waste as defined here includes household kitchen waste and food waste from restaurants, markets and schools. Food waste comprises about $40 \%$ of Taipei's municipal solid waste (MSW); the total food waste generated daily in Taipei City is 1316 tons. Recycling food waste will result in a significant reduction in MSW. Five alternatives exist for treating food waste: incineration (INC), landfill (LAN), composting (COM), hog feeding (HOG), and anaerobic digestion (ANA).

The algorithm used to find the optimal food waste management schemes is as follows.

\subsection{Formulate model for waste problems}

This study adopts four objectives, i.e., environmental, economic, social, and technological factors. Environmental 
factors involve human health, resource consumption and ecological impacts. Economic factors include costs and benefits of the waste management processes and marketing potential for byproducts. The social factors comprise social justice, social welfare and social acceptability, and, finally, technological factors encompass land demand and technology maturity.

\subsection{Prioritize the alternatives}

The fuzzy AHP approach is used to prioritize alternatives and is described as follows.

\subsubsection{Build the hierarchical structure of the waste problems}

Fig. 4 presents the hierarchy of the food waste management problems in Taipei City.

\subsubsection{Calculate the criteria weights}

Criteria weights are determined using questionnaires to obtain stakeholder opinions (government, D1; experts, D2; NGOs, D3; and business, D4). Priorities assigned to each criterion by these stakeholders are integrated to develop fuzzy criteria weights (Table 3).
Table 3

Fuzzy criteria weights for evaluating food waste management methods

Criteria Fuzzy criteria weights

Human health $(\mathrm{C} 1)$

Resource consumption $(\mathrm{C} 2)$

Ecological impact (C3)

System costs (C4)

System benefits (C5)

Marketing potential of the byproducts (C6)

Social justice (C7)

Social welfare $(\mathrm{C} 8)$

Social acceptability (C9)

Land demand $(\mathrm{C} 10)$

Technology maturity (C11)

$(0.016,0.148,0.481)$

$(0.012,0.062,0.277)$

$(0.026,0.134,0.481)$

$(0.004,0.026,0.179)$

$(0.004,0.042,0.257)$

$(0.005,0.047,0.298)$

$(0.006,0.065,0.280)$

$(0.004,0.025,0.177)$

$(0.006,0.053,0.288)$

$(0.008,0.060,0.504)$

$(0.011,0.051,0.529)$

\subsubsection{Determine the performance of alternatives for each criterion}

The performance on environmental objective was determined by life cycle assessment with the eco-indicator 99 calculated using SimaPro 5.1. The performance of economic and technological objectives was calculated using the data from the Bureau of Environmental Protection of Taipei City (Yang et al., 2002). System cost contains construction and operating costs, and system benefit is defined

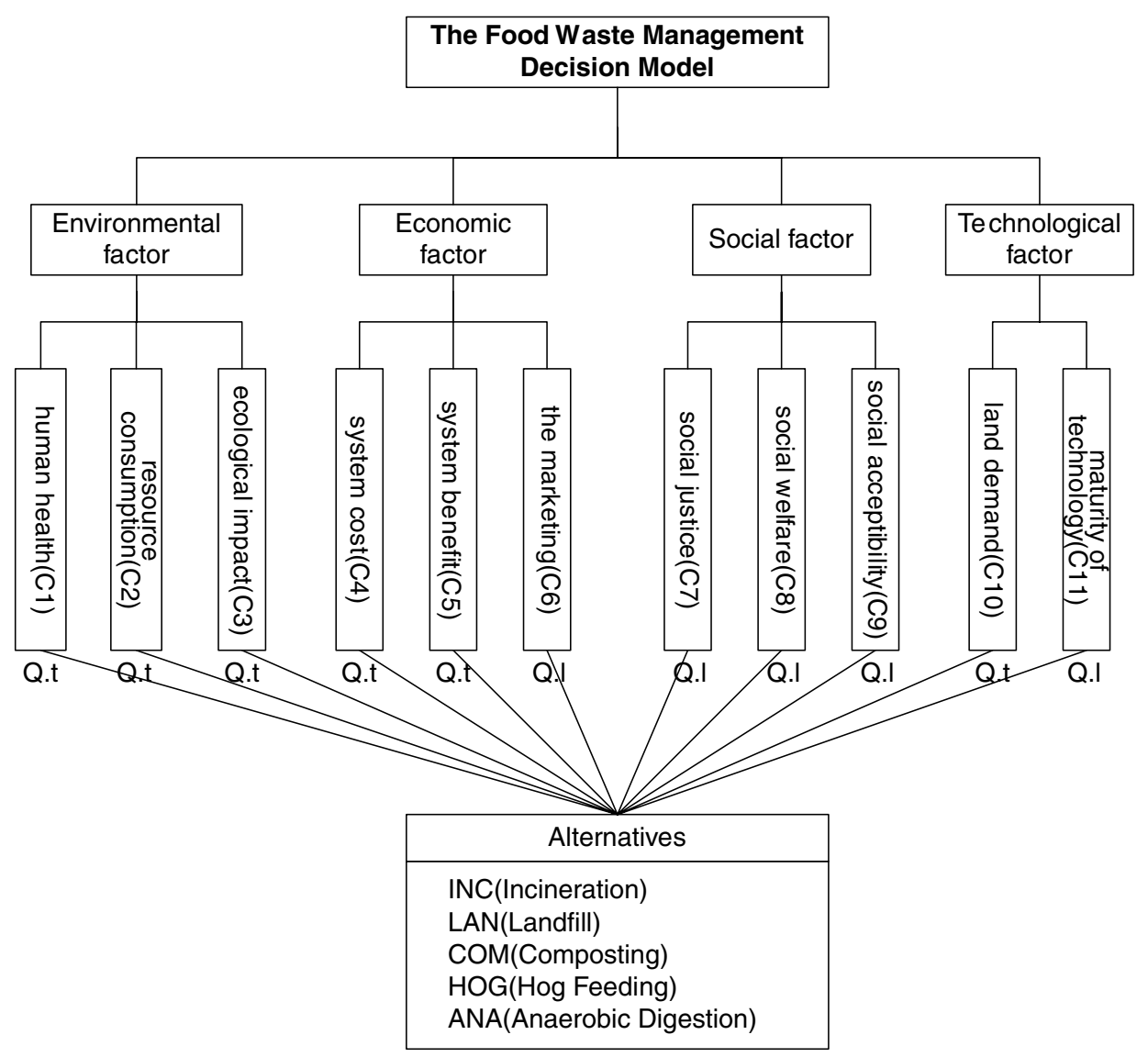

Q.t:quantitative Q.1:qualitative

Fig. 4. Fuzzy AHP hierarchy of food waste management problems. 
as the profit from treatment units. Performance of alternatives for quantitative criteria is determined by Eqs. (7) and (8). The triangular fuzzy number is utilized to express the performance of quantitative criteria $(\mathrm{C} 1-\mathrm{C} 5, \mathrm{C} 10)$. Linguistic variables are used to calculate performance of qualitative criteria (C6-C9, C11). Table 4 displays the fuzzy performance of all criteria.

4.2.4. Aggregate fuzzy weights, fuzzy performance and rank final scores for alternatives

Fuzzy weighting and fuzzy performance can be aggregated to obtain final scores for alternatives using Eq. (10). Fig. 5 shows the result for food-waste management. Food waste management alternatives are ranked as follows:

$\mathrm{ANA} \succ \mathrm{INC} \succ \mathrm{HOG} \succ \mathrm{COM} \succ \mathrm{LAN}$

\subsection{Consensus analysis model}

Four stakeholder groups filled out the questionnaire. Table 5 lists the preferences of the alternatives for each stakeholder. Fig. 6(a)-(e) show the consensus diagrams that resulted from the consensus analysis, including information of the consensus degree and the consensus results for the case study. The numbers on the left of
Table 5

Preferences of the alternatives for individual stakeholders for food waste management in Taipei City

\begin{tabular}{clllll}
\hline Stakeholders & INC & LAN & COM & HOG & ANA \\
\hline D1 & & & & & \\
D11 & & Moderate & Good & Good & Good \\
Bad & & & & \\
D12 & Bad & Bad & Good & Good & Good \\
D13 & Very & Moderate & Good & Very good & bad \\
& bad & & & & \\
D2 & & & & & \\
D21 & Bad & Moderate & Moderate & Very good & Bad \\
D22 & Bad & Bad & Good & Moderate & Good \\
D23 & & Moderate & Very bad & Good & Good \\
Good & Very & Moderate & Bad & Very bad & Good \\
D24 & good & Boderate & Good & Good & Good \\
D25 & Bad & Mod & & \\
D3 & & & & Bod & Moderate \\
D31 & Bad & Bad & Good & Bad \\
D32 & Very & Bad & Good & Good & Good \\
& bad & & & & \\
D4 & & & & & \\
D41 & Bad & Bad & Very good & Very good & Moderate \\
D42 & Bad & Bad & Moderate & Good & Very \\
& & & & & good \\
\hline
\end{tabular}

* D1, government; D2, experts; D3, NGOs; D4, business.

Table 4

Fuzzy performance of food waste management alternatives

\begin{tabular}{llllll}
\hline Criteria & INC & LAN & COM & HOG & ANA \\
\hline C1 & $(0.439,0.488,0.537)$ & $(0.200,0.222,0.244)$ & $(0.000,0.000,0.000)$ & $(0.845,0.939,1.000)$ & $(0.900,1.000,1.000)$ \\
C2 & $(0.728,0.809,0.890)$ & $(0.000,0.000,0.000)$ & $(0.567,0.630,0.693)$ & $(0.900,1.000,1.000)$ & $(0.749,0.832,0.915)$ \\
C3 & $(0.798,0.887,0.976)$ & $(0.000,0.000,0.000)$ & $(0.748,0.831,0.914)$ & $(0.900,1.000,1.000)$ & $(0.809,0.899,0.988)$ \\
C4 & $(0.375,0.416,0.458)$ & $(0.000,0.000,0.000)$ & $(0.900,1.000,1.000)$ & $(0.247,0.274,0.302)$ & $(0.220,0.244,0.269)$ \\
C5 & $(0.016,0.018,0.020)$ & $(0.000,0.000,0.000)$ & $(0.002,0.002,0.002)$ & $(0.900,1.000,1.000)$ & $(0.061,0.068,0.075)$ \\
C6 & $(0.000,0.446,1.000)$ & $(0.000,0.450,1.000)$ & $(0.250,0.623,1.000)$ & $(0.000,0.602,1.000)$ & $(0.000,0.542,1.000)$ \\
C7 & $(0.250,0.612,1.000)$ & $(0.250,0.500,0.750)$ & $(0.250,0.612,1.000)$ & $(0.000,0.125,0.500)$ & $(0.250,0.500,0.750)$ \\
C8 & $(0.000,0.250,0.500)$ & $(0.000,0.250,0.500)$ & $(0.500,0.866,1.000)$ & $(0.000,0.354,0.750)$ & $(0.000,0.433,1.000)$ \\
C9 & $(0.250,0.707,1.000)$ & $(0.000,0.250,0.500)$ & $(0.250,0.612,1.000)$ & $(0.000,0.433,1.000)$ & $(0.250,0.612,1.000)$ \\
C10 & $(0.900,1.000,1.000)$ & $(0.678,0.754,0.829)$ & $(0.878,0.976,1.000)$ & $(0.000,0.000,0.000)$ & $(0.890,0.989,1.000)$ \\
C11 & $(0.500,0.794,1.000)$ & $(0.250,0.692,1.000)$ & $(0.000,0.472,1.000)$ & $(0.250,0.588,1.000)$ & $(0.000,0.379,0.750)$ \\
\hline
\end{tabular}

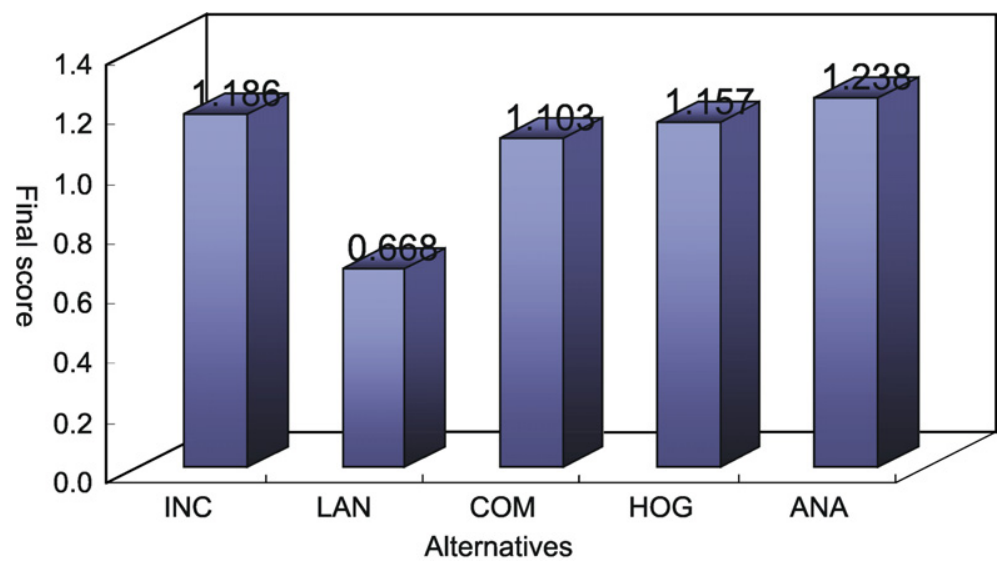

Fig. 5. Final scores of the food waste management alternatives. 


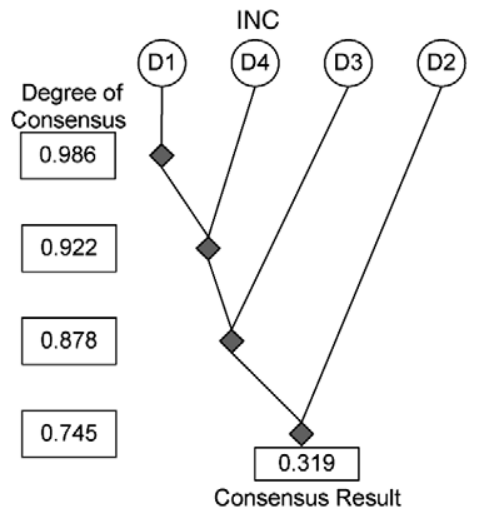

a

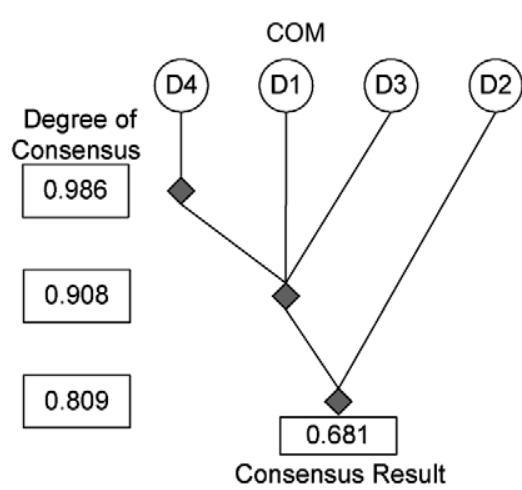

c

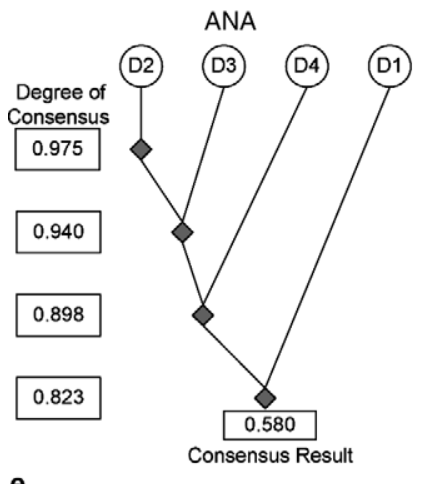

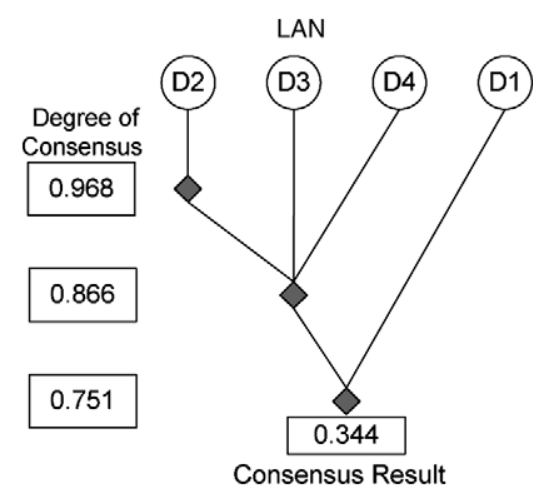

b

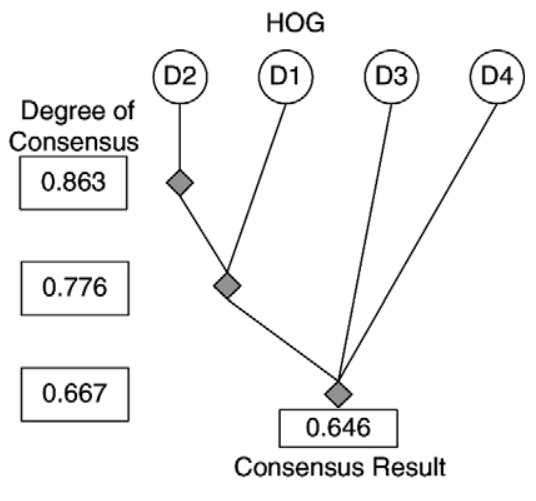

d

*D1: government

D2: experts

D3: NGOs

D4: business

Fig. 6. (a) Consensus diagram for INC. (b) Consensus diagram for LAN. (c) Consensus diagram for COM. (d) Consensus diagram for HOG. (e) Consensus diagram for ANA. * D1, government; D2, experts; D3, NGOs; D4, business.

the consensus diagram indicate the degree of consensus. Taking INC for example, the D2 group has the furthest semantic distance, indicating the lowest degree of consensus and, thus, D2 will have the highest possibility of causing conflict. The final consensus result and the degree of consensus for the four stakeholders for INC are 0.319 and 0.745 , respectively. The interpretation of the results is that the stakeholders do not accept INC as a food waste treatment method. The degrees of consensus for these five alternatives are all larger than 0.426 , meaning an acceptable compromise may have been reached. The degree of consensus for ANA is higher than that of the other alternatives and, hence, ANA is more acceptable than the other alternatives.

\subsection{Communicate and decision-making}

The alternative scores (excluding LAN) calculated by fuzzy AHP method are close; however, INC is better than HOG, COM and LAN in the traditional thinking. According to the CAM developed in this study, stakeholders tend to not accept INC and LAN. After stakeholders communicated, ANA, HOG and COM were the preferred treatment methods for food waste management.

\section{Conclusion}

The novel sustainable decision-making model is a combination of MCDM and CAM. The proposed model 
provides an effective means of assisting decision making for real world waste management problems. The CAM can quantify degree of consensus and consensus results for stakeholders perspectives regarding alternatives and identify the source of possible conflicts. The sustainable decision-making model not only accommodates economic, environmental and social factors simultaneously, but also incorporates public participation into the decision-making process. This model can seek the compromise alternative for stakeholders and attempt to look for a balance between the scientific decision-making model and stakeholder value, and sustainable waste management can be achieved by using this model. The proposed model can also be applied to environment impact assessment (EIA) and other environmental problems, such as water management or air emission control problems.

\section{Acknowledgements}

The authors thank the Bureau of Environmental Protection of Taipei City, Taiwan for financially supporting this research. The authors also thank the anonymous reviewers and the editor for their constructive suggestions.

\section{References}

Alidi, A., 1996. A multiobjective optimization model for the waste management of the petrochemical industry. Applied Mathematical Modelling 20, 925-933.

Ananda, J., Herath, G., 2003. Incorporating stakeholder values into regional forest planning: a value function approach. Ecological Economics 45, 75-90.

Barton, J., Dalley, D., Patel, V., 1996. Life cycle assessment for waste management. Waste Management 16, 35-50.

Beccali, M., Cellura, M., Ardente, D., 1998. Decision making in energy planning: the ELECTRE multicriteria analysis approach compared to a fuzzy-sets methodology. Energy Conversion and Management 39, 1869-1881.

Bellehumeur, C., Vasseur, L., Ansseau, C., Marcos, B., 1997. Implementation of a multicriteria sewage sludge management model in the southern Quebec municipality of Lac-Megantic, Canada. Journal of Environmental Management 50, 51-66.

Berger, C., Savard, G., Wizere, A., 1999. EUGENE: an optimization model for integrated regional solid waste management planning. International Journal of Environment and Pollution 12, 280-307.

Bordogna, G., Fedrizzi, M., Pasi, G., 1997. A linguistic modeling of consensus in group decision making based on OWA operators. IEEE Transactions on Systems Man and Cybernetics Part A - Systems and Humans 27, 126-132.

Brans, J.P., Vincke, P., 1985. A preference ranking organization method: the ROMETHEE method for MCDM. Management Science 31, 647656.

Bryson, N., 1996. Group decision-making and the analytic hierarchy process: Exploring the consensus-relevant information content. Computers \& Operations Research 23, 27-35.

Buckley, J.J., 1985. Fuzzy hierarchical analysis. Fuzzy Sets and System 17, 233-247.

Chang, C.T., Hwang, J.R., 1996. A multiobjective programming approach to waste minimization in the utility systems of chemical processes. Chemical Engineering Science 51, 3951-3965.

Chang, N.B., Wang, S.F., 1996. Solid waste management system analysis by multiobjective mixed integer programming model. Journal of Environmental Management 48, 17-43.
Chang, N.B., Wei, Y.L., 1999. Strategic planning of recycling drop-off stations and collection network by multiobjective programming. Environmental Management 24, 247-263.

Chiclana, F., Herrera, V.E., Herrera, F., Alonso, S., 2004. Induced ordered weighted geometric operators and their use in the aggregation of multiplicative preference relations. International Journal of Intelligent Systems 19, 233-255.

Chiou, H.K., Tzeng, G.H., 2002. Fuzzy multiple-criteria decision-making approach for industrial green engineering. Environmental Management 30, 816-830.

Dalemo, M., Sonesson, U., Bjorklund, A., Mingarini, K., Frostell, B., Jonsson, H., Nybrant, T., Sundqvist, J., Thyselius, L., 1997. ORWARE-A simulation model for organic waste handling systems Part 1: Model description. Resources, Conservation and Recycling 21, $17-37$.

Eriksson, O., Frostell, B., Björklund, A., Assefa, G., Sundqvist, J., Granath, J., Carlsson, M., Baky, A., Thyselius, L., 2002. ORWARE a simulation tool for waste management. Resources, Conservation and Recycling 36, 287-307.

Esmaili, H., 1972. Facility selection and haul optimisation model. Journal of the Sanitary Engineering Division-ASCE, 1005-1021.

Finnveden, G., 1999. Methodological aspects of life cycle assessment of integrated solid waste management systems. Resources, Conservation and Recycling 26, 173-187.

Geldermann, J., Spengler, T., Rentz, O., 2000. Fuzzy outranking for environmental assessment. Case study: iron and steel making industry. Fuzzy Sets and Systems 115, 45-65.

Haastrup, P., Maniezzo, V., Mattarelli, M., Rinaldi, F.M., Mendes, I., Paruccini, M., 1998. A decision support system for urban waste management. European Journal of Operational Research 109, 330 341.

Hasit, Y., Warner, D., 1981. Regional solid waste planning with WRAP. Journal of Environmental Engineering-ASCE 107, 511-525.

Helms, B., Clark, R., 1974. Locational models for solid waste management. Journal of Urban Planning and Development-ASCE 97, 1-13.

Herrera, F., Herrera, V.E., Chiclana, F., 2003. A study of the origin and uses of the ordered weighted geometric operator in multicriteria decision making. International Journal of Intelligent Systems 18, 689 707.

Hwang, C.L., Yoon, K., 1981. Multiple Attribute Decision MakingLecture Notes in Economics and Mathematical Systems. Springer, Berlin.

Jenkins, L., 1982. Parametric mixed integer programming: an application to solid waste management. Management Science 28, 1270-1284.

Klang, A., Vikman, P., Brattebø, H., 2003. Sustainable management of demolition waste-an integrated model for the evaluation of environmental, economic and social aspects. Resources, Conservation and Recycling 38, 317-334.

Morrissey, A., Browne, J., 2004. Waste management models and their application to sustainable waste management. Waste Management 24, 297-308.

Perlack, R., Willis, C., 1985. Multiobjective decision-making in waste disposal planning. Journal of Environmental Engineering-ASCE 111, 373-385.

Powell, J., 2000. The potential for using life cycle inventory analysis in local authority waste management decision making. Journal of Environmental Planning and Management 43, 351-367.

Powell, J., Craighill, A., Parfitt, J., Turner, R., 1996. A lifecycle assessment and economic valuation of recycling. Journal of Environmental Planning and Management 39, 97-112.

Roy, B., 1991. The outranking approach and the foundations of ELECTRE methods. Decision Theory 31, 49-73.

Saaty, T.L., 1980. The Analytic Hierarchy Process. McGraw-Hill, New York.

Solvmosi, T., Dombi, J., 1986. A method for determining the weights of criteria: the centralized weights. European Journal of Operational Research 26, 35-41. 
Sonesson, U., Dalemo, M., Mingarini, K., Jonsson, H., 1997. ORWAREA simulation model for organic waste handling systems Part 2: case study and simulation results. Resources, Conservation and Recycling 21, 39-54.

Tavana, M., Kennedy, D.T., Joglekar, P., 1996. A group decision support framework for consensus ranking of technical manager candidates. Omega-International Journal of Management Science 24, 523-538.

Tran, L.T., Knight, C.G., O'Neill, R.V., Smith, E.R., Riitters, K.H., Wickham, J., 2002. Fuzzy decision analysis for integrated environmental vulnerability assessment of the Mid-Atlantic region. Environmental Management 29, 845-859.

Truitt, M., Liebnman, J., Kruse, C., 1969. Simulation model of urban refuse collection. Journal of the Sanitary Engineering Division-ASCE, 289-298.

Vaillancourt, K., Waaub, J., 2002. Environmental site evaluation of waste management facilities embedded into EUGENE model: a multicriteria approach. European Journal of Operational Research $139,436-448$.

Vasseur, L., Lafrance, L., Ansseau, C., Renaud, D., Morin, D., Audet, T., 1997. Advisory committee - a powerful tool for helping decision makers in environmental issues. Environmental Management 21, 359 365.

Wilson, E., McDougall, F., Willmore, J., 2001. Euro-trash searching Europe for a more sustainable approach to waste management. Resources, Conservation and Recycling 31, $327-$ 346.

Yang, W.F. et al., 2002. The Study of Hazardous Composition of the Food Waste and its Byproduct and the Strategy Planning of Food Waste Management. Bureau of Environmental Protection of Taipei City, Taiwan.

Zimmermann, H.J., 1987. Fuzzy Sets, Decision Making, and Expert Systems. Kluwer Academic, Boston. 